\title{
1- and 2-Azetines via Visible Light-Mediated [2+2]-Cycloadditions of Alkynes and Oximes
}

\author{
Emily R. Wearing, Dominique E. Blackmun, Marc R. Becker, and Corinna S. Schindler* \\ University of Michigan, Department of Chemistry, Willard Henry Dow Laboratory, 930 North University Ave., Ann Arbor, \\ MI 48109, US.
}

\begin{abstract}
Azetines, four-membered unsaturated nitrogen-containing heterocycles, hold great potential for drug design and development, but remain underexplored due to challenges associated with their synthesis. We report an efficient, visible light-mediated approach towards 1 - and 2-azetines relying on alkynes and the unique triplet state reactivity of oximes, specifically 2-isoxazolines. While 2-azetine products are accessible upon intermolecular [2+2]-cycloaddition via triplet energy transfer from a commercially available iridium photocatalyst, the selective formation of 1-azetines proceeds upon a second, consecutive, energy transfer process. Mechanistic studies are consistent with a stepwise reaction mechanism via $\mathrm{N}-\mathrm{O}$ bond homolysis following the second energy transfer event to result in the formation of 1-azetine products. Characteristic for this method is its operational simplicity, mild conditions and modular approach that allows for the synthesis of functionalized azetines and tetrahydrofurans via in situ hydrolysis from readily available precursors.
\end{abstract}

Output in the pharmaceutical industry has been decreasing due to various challenges, including the attrition of lead compounds resulting in low numbers of drug candidates reaching the market. ${ }^{1,2}$ Increasing the potency, metabolic stability, and novelty of future drug candidates is essential to combat this problem. ${ }^{3,4}$ The incorporation of new building blocks has been shown to enable scaffold hopping ${ }^{5,6}$, which can lead to the discovery of equipotent compounds with improved properties. ${ }^{7,3}$ Additionally, incorporating novel scaffolds into drug screening programs is beneficial as it provides insights into new areas of chemical space. ${ }^{3}$ Among these desirable new building blocks are azetidines (1), four-membered nitrogen heterocycles, exhibiting advantageous properties for pharmaceutical applications (Fig. 1A) ${ }^{8-14}$ Although their unsaturated analogs 1- and 2-azetines ( $\mathbf{2}$ and $\mathbf{3}$ ) are crucial components of biological processes,${ }^{15-17}$ they remain highly underexplored in medicinal chemistry despite displaying desirable characteristics ${ }^{18}$ including increased ring strain and rigidity along with lower basicity than their azetidine counterparts. ${ }^{19}$ To explore the full potential of azetine scaffolds, new and improved synthetic methods for their construction are required. Currently available approaches to access 1azetines include $\beta$-eliminations ${ }^{20-22}$ (4), thermolysis of cyclopropyl azides ${ }^{23-25}(5)$, and ring expansion reactions of aziridines ${ }^{26}(\mathbf{6})$ (Fig. 1B). Synthesis of 2-azetines is similarly limited, relying on eliminations ${ }^{27-33}(7)$, and metal mediated cycloadditions via ring expansion of diazoaziridines (8). Arguably, [2+2]-cycloadditions between alkenes and nitriles ${ }^{34,35}$ or alkynes and imines ${ }^{36-38}$ represent the most efficient strategies to access 1- and 2-azetines, however they suffer from a limited scope and the competing formation of azadiene byproducts ${ }^{39}$ (12 and 16, Fig. 1C). ${ }^{40}$ To date, there exists no general, efficient synthetic protocol to access azetines via intermolecular [2+2]-cycloadditions. ${ }^{41,42}$ Herein we report the development of the first visible-light mediated approach towards 1- and 2azetines that harnesses the triplet state reactivity of 2-isoxazolines (18) with alkynes (17). This method represents a significant advance as the first general photochemical [2+2] cycloaddition method that overcomes existing challenges associated with the un-
Figure 1. 1- and 2-Azetines as desirable $N$-containing heterocycles.
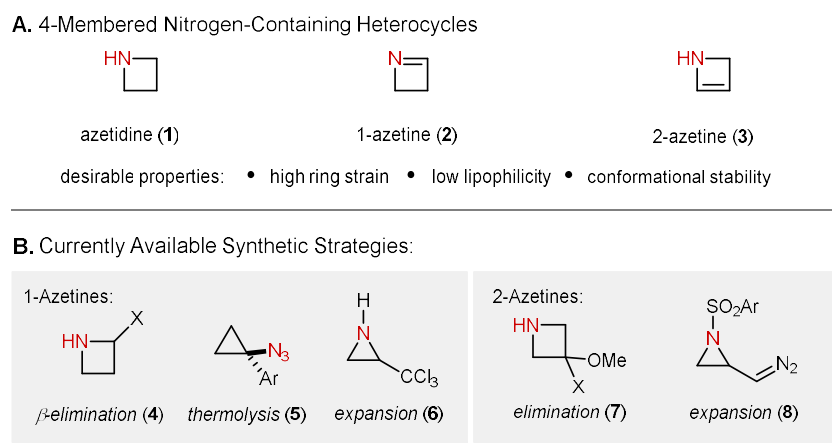

C. Challenges of $[2+2]-C y c l o a d d i t i o n$ Approaches:

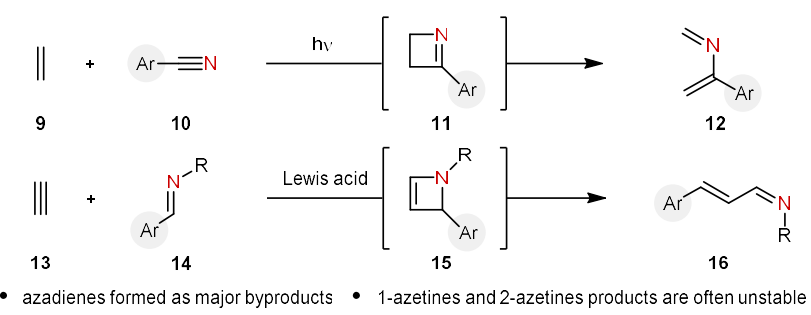

- azadienes formed as major byproducts - 1 -azetines and 2-azetines products are often unstable

D. This work: Divergent Access to 1- or 2-Azetines via [2+2]-Cycloadditions

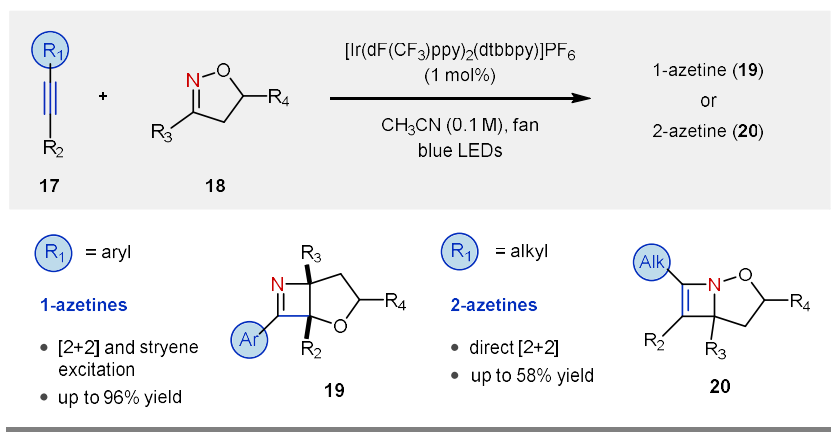


Figure 2. Initial Observation and Mechanistic Hypothesis for 1Azetine Formation in Visible Light-Enabled [2+2]-Cycloadditions.

A. Initial Observation of 1-Azetine Formation
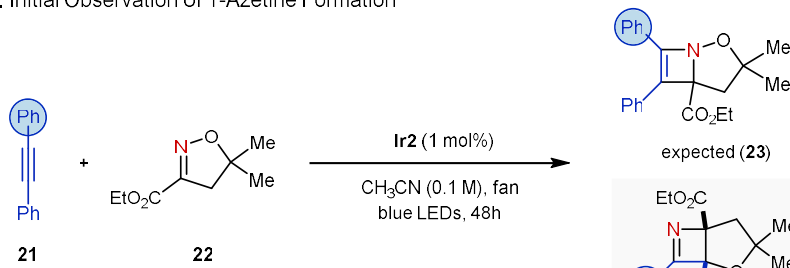

expectec (23)

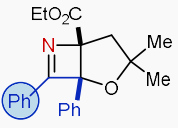

observec $(\mathbf{2 4}, \mathbf{4 9 \%})$

B. Mechanistic Hypotheses: Stepwise vs. Concerted Reaction Pathway

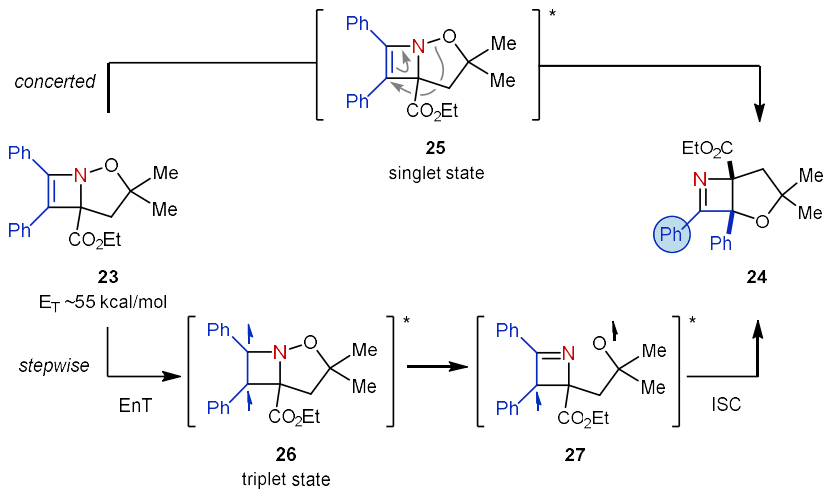

desired ring-opening of the strained azetine products (Fig. 1D). Specifically, 1-azetines (19) are accessible from aryl alkynes while their aliphatic analogs result in the selective formation of 2 -azetines (20).

Initial investigations into the development of intermolecular [2+2]cycloadditions to access 2 -azetines commenced with subjecting diphenylacetylene $\mathbf{2 1}$ and isoxazoline $\mathbf{2 2}$ to reaction conditions previously identified as optimal for aza Paternò-Büchi reactions with 18. However, analysis of the reaction products revealed that rather than the expected 2 -azetine product $\mathbf{2 3}, 1$-azetine $\mathbf{2 4}$ was isolated as the only product in $49 \%$ yield (Fig. 2A). We hypothesized that this transformation initially proceeds via [2+2]-cycloaddition of the triplet state 2-isoxazoline to diphenylacetylene 21, generating 2azetine 23 (Fig. 2B). The triplet state energy of the styrene moiety incorporated into 23 is expected to be $55 \mathrm{kcal} / \mathrm{mol}$ based on the reported triplet energy of cis-stilbene, ${ }^{43}$ which is in the range of the iridium photocatalyst. Thus, 2-azetine $\mathbf{2 3}$ can undergo a second sensitization from the iridium photocatalyst to trigger a stepwise reaction pathway relying on triplet-triplet energy transfer to form triplet state biradical 26. Subsequent $\mathrm{N}-\mathrm{O}$ bond scission results in a second biradical 27, which undergoes radical recombination to form 1-azetine $\mathbf{2 4}$. Alternatively, 2-azetine $\mathbf{2 3}$ could be directly excited to its singlet state 25, which upon concerted $\mathrm{N}-\mathrm{O}$ bond fragmentation and $\mathrm{C}-\mathrm{O}$ bond formation results in 1-azetine 24. Notably, no competing azetine ring-opening and associated azadiene formation was observed, highlighting the potential of this strategy to enable efficient synthetic access to highly functionalized 1-azetine products.

Subsequent efforts focused on the optimization of reaction conditions for 1-azetine formation (Table 1). Evaluation of a variety of commercially available and literature reported catalysts revealed $\left[\operatorname{Ir}\left(\mathrm{dF}\left(\mathrm{CF}_{3}\right)\right)_{2}(\mathrm{dtbbpy})\right] \mathrm{PF}_{6}\left(\operatorname{Ir} \mathbf{1} \cdot \mathrm{PF}_{6}\right)$ as the superior photocatalyst for this transformation, providing $\mathbf{2 9}$ in $56 \%$ yield (Table 1, entry
2). Interestingly, $\operatorname{Ir}(\mathrm{dFppy})_{3}$ (Ir2) previously identified as optimal in the development of intermolecular aza Paternò-Büchi reactions resulting in azetidines resulted in $33 \%$ yield of $29 .{ }^{44,45}$ Based on these results, we hypothesized that the observed increase in yield for $\mathbf{I r} \mathbf{1} \cdot \mathrm{PF}_{6}$ relative to $\mathbf{I r} \mathbf{2}$ was due to an improved second energy transfer step of the intermediate styrene, as $\operatorname{Ir} 1 \cdot \mathrm{PF}_{6}$ was previously identified as optimal for intramolecular aza Paternò-Büchi reactions relying on styrene sensitization. ${ }^{46}$ In comparison, despite exhibiting a high triplet energy, $\left[\operatorname{Ir}(\mathrm{dF}(\mathrm{Me}) \mathrm{ppy})_{2}\right.$ (dtbbpy) $] \mathrm{PF}_{6}$ led to a slight decrease in yield (Table 1, entry 1). Similarly, catalysts with lower triplet energies also provided the product in slightly diminished yields (Table 1, entry 4-5). Interestingly, a catalyst with a similar triplet energy to $\left[\operatorname{Ir}(\mathrm{dFppy})_{2}(\mathrm{dttbbpy})\right] \mathrm{PF}_{6}$, fac- $\left[\operatorname{Ir}\left(4^{\prime}-\right.\right.$ $\mathrm{CF}_{3}$ ppy) 3 ] failed to provide the desired product (Table 1 , entry 6) similarly to the catalyst with the lowest triplet energy (Table 1, entry 7). Importantly, successful product formation was found to be independent of catalyst redox potential, while the highest yielding catalysts generally had high triplet energies around $60 \mathrm{kcal} / \mathrm{mol}$, which is consistent with a triplet-triplet energy transfer (TTEnT) mechanism. Additionally, direct excitation of the reaction mixture with UV-light was unsuccessful, demonstrating that this reactivity is uniquely accessible by TTEnT (Table 1, entry 8).

Table 1. Optimization of Reaction Conditions for 1-Azetine Formation.

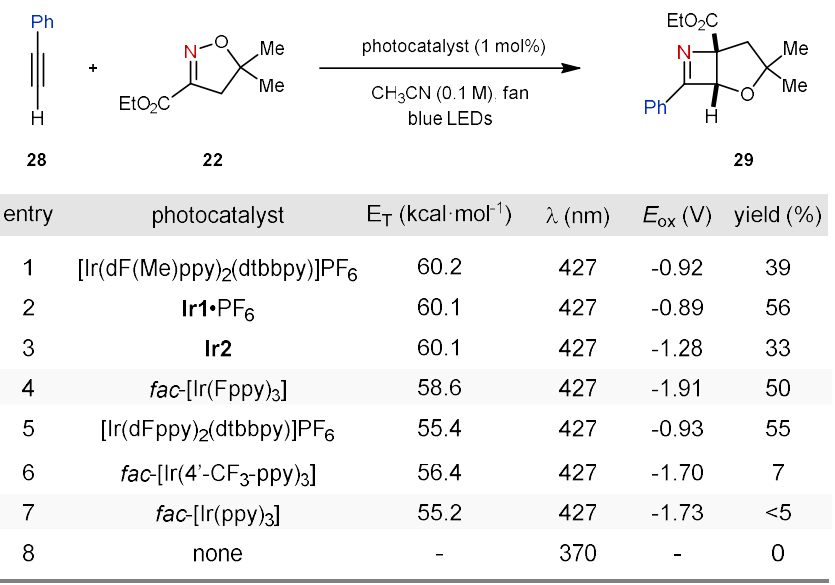

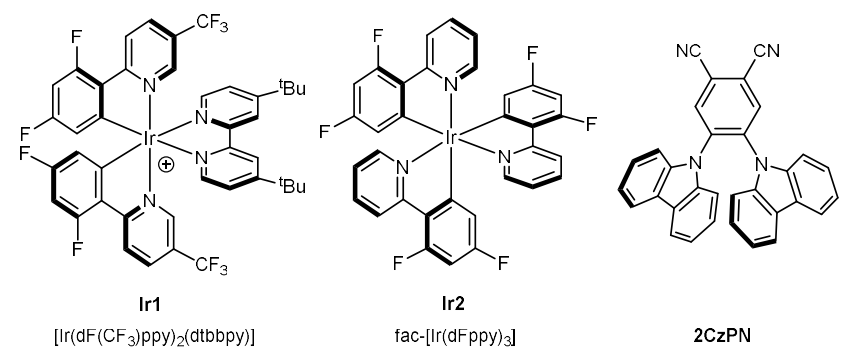

Conditions: $0.1 \mathrm{mmol} 22$ and photocatalyst are disscolved in acetonitrile $(0.1 \mathrm{M})$ and the solution was sparged for $10 \mathrm{~min} .0 .15 \mathrm{mmol}$ phenylacetylene (28) is added and the sample irradiated with blue LED lamps 16 hours. Percent yield was determined by NMR with mesitylene internal standard.

With optimal reaction conditions in hand, we set out to explore the substrate scope for 1-azetine formation (Table 2). This new visible light-mediated method allows access to a range of 1-azetines in up to $96 \%$ yield. The reaction was found to tolerate a range of aryl alkyne coupling partners, including terminal and internal aryl alkynes. Specifically, alkynes bearing functional groups such as esters (32), amides (34), ketones (31) and free alcohols (33) were all tolerated by the optimal reaction conditions to form the desired products in up to $86 \%$ yield. Notably, alkynes incorporating an additional activating group such as an aryl ring (24), ester (32), amide 
Table 2. Investigation of the Substrate Scope for 1-Azetine Formation via in Visible Light-Enabled [2+2]-Cycloadditions.

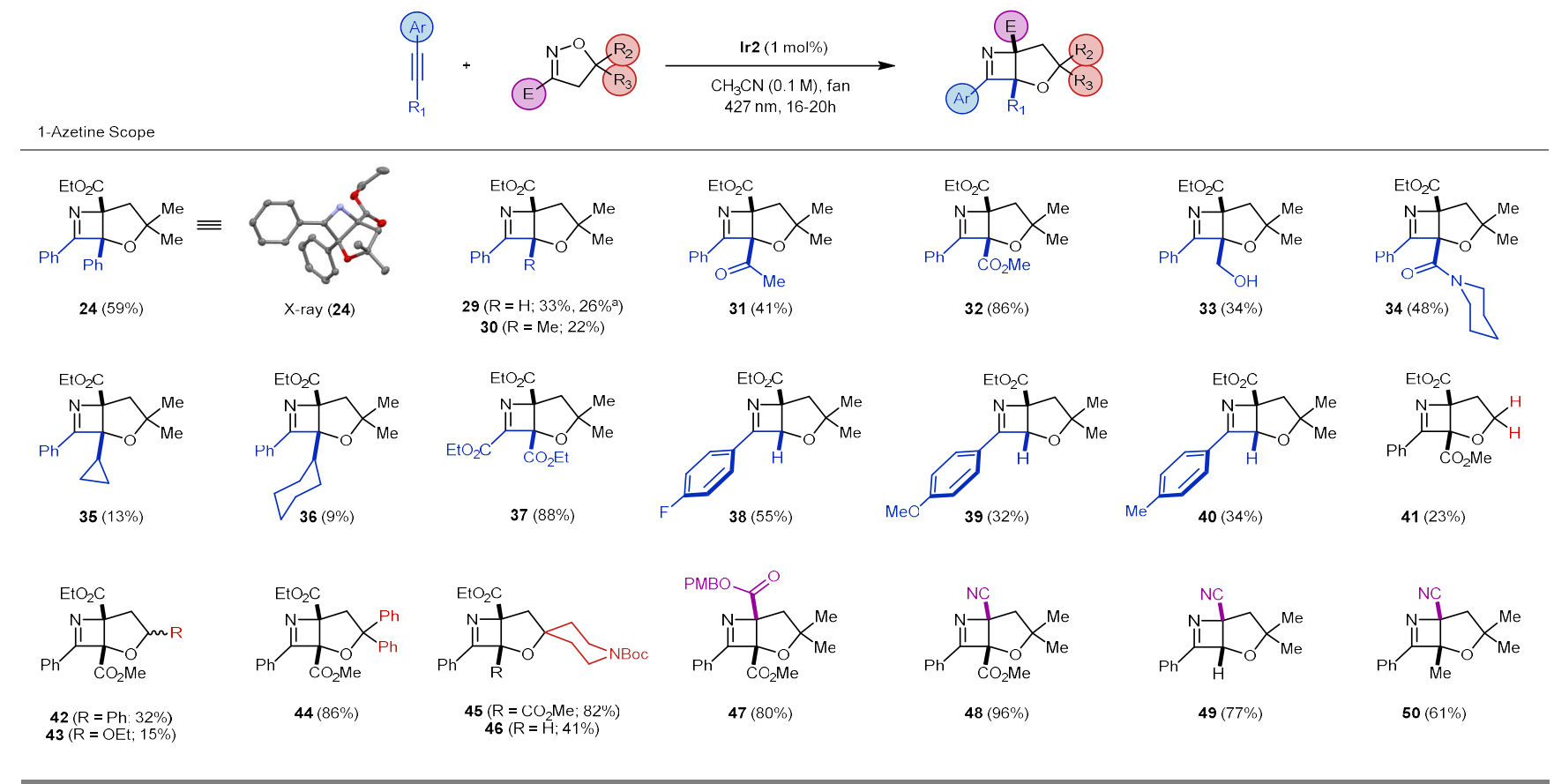

Conditions: $\quad 0.25 \mathrm{mmol}$ isoxazoline and $\mathrm{Ir} 1 \cdot \mathrm{PF}_{6}(1 \mathrm{~mol} \%)$ are dissolved in acetonitrile $(0.1 \mathrm{M})$ and the solution is sparged for $10 \mathrm{~min}$. $0.375 \mathrm{mmol}$ alkyne is added and the reaction irradiated with blue LED lamps $(427 \mathrm{~nm})$ for $16-20$ hours ${ }^{a}$ Conditions for 2 CzPN photocatalyst: 2 CzPN (1 mol \%), Toluene (0.2 M), $427 \mathrm{~nm}$ LED, fan, 20 hrs.

(34) or a ketone (31) were found to be higher yielding with yields up to $86 \%$. Sterically demanding internal alkynes $(\mathbf{3 0}, \mathbf{3 5 - 3 6})$ were amenable to the reaction conditions, albeit resulting in decreased yields. Moreover, aryl alkynes incorporating electron-donating groups in the para position resulted in up to $34 \%$ yield $(\mathbf{3 9}, \mathbf{4 0})$ while an electron-withdrawing substituent proved superior $(\mathbf{3 8})$ and resulted in 55\% yield. Importantly, an alkyne lacking an aryl activating group but incorporating two ester groups allowed formation of the product in an excellent yield of $88 \%$ (37) demonstrating that aryl alkynes are not required if the resulting intermediates can be sensitized through TTEnT. With respect to the 2-isoxazole coupling partner, both unsubstituted (41) and monosubstituted $(42,43)$ substrates were tolerated, albeit proceeding with overall decreased yields. 2-Isoxazolines differing in their substitution in the 5- position including a diphenyl substituted isoxazoline (44) and a piperidine substituted isoxazoline (45) reacted smoothly to their respective products resulting in $86 \%$ and $82 \%$ yield, respectively. Importantly, the incorporation of a bulkier backbone was found to increase the yield for reactions relying on phenylacetylene, resulting in $\mathbf{4 6}$ in $41 \%$ yield relative to $\mathbf{2 9}$, which was formed in 33\% yield. 2-Isoxazolines bearing distinct electron withdrawing groups including PMB protected esters and cyano groups proved excellent substrates generating products $\mathbf{4 7 - 5 0}$ in up to $96 \%$ yield. Use of the cyano substituted isoxazoline allowed for improved yields when reacted with phenylacetylene and its methyl-substituted analog resulting in the formation of $\mathbf{4 9}$ and $\mathbf{5 0}$ in $77 \%$ and $61 \%$ yield, respectively. Notably, the isolated yields shown in Table 2 were found to be lower than those observed by NMR analysis of the crude reaction mixture, which can be attributed to challenges associated with the isolation of 1-azetines upon column chromatography (e.g. 33\% isolated yield for 29 vs. 56\% NMR yield). Excitingly, using an organic photocatalyst, $2 \mathrm{CzPN}$, allowed the synthesis of $\mathbf{2 9}$ in yields comparable to $\mathbf{I r} 1 \cdot \mathrm{PF}_{6}$ relying on toluene as reaction solvent and a concentration of $0.2 \mathrm{M}$. This demonstrates the possibility to potentially use a more cost-effective and metal-free catalyst for large scale applications.
Based on our mechanistic hypothesis (Fig. 2), alkynes bearing aliphatic substituents are expected to afford 2-azetine products, as the resulting alkyl alkenes have excited states that are not accessible by triplet energy transfer from $\mathbf{I r} 1 \cdot \mathrm{PF}_{6}$. Exploring this hypothesis, we investigated the ability of previously developed reaction conditions

Table 3. Optimization of Reaction Conditions for 2-Azetine Formation.

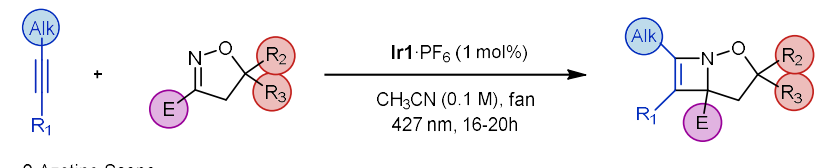

2-Azetine Scope

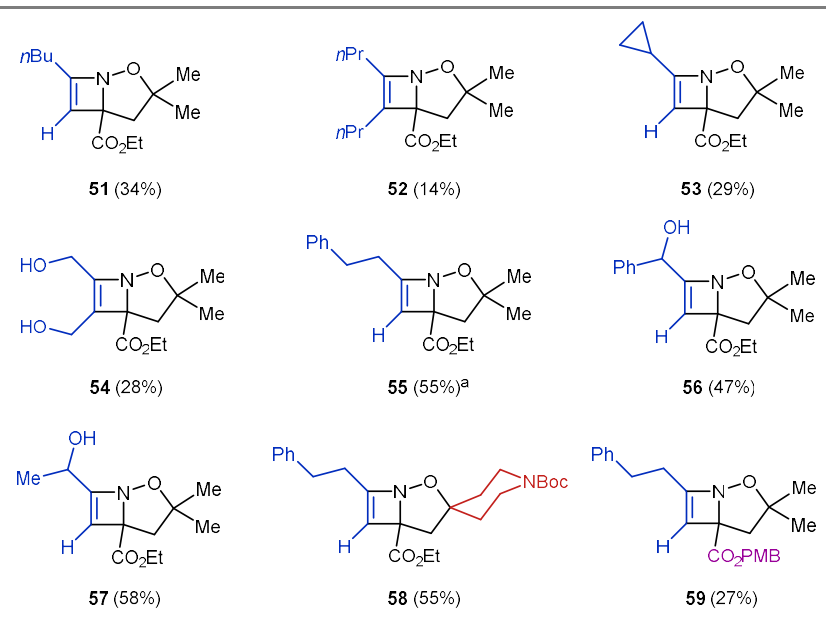

Conditions: $\quad 0.25 \mathrm{mmol}$ isoxazoline and $\mid \mathrm{r} 1 \cdot \mathrm{PF}_{6}(1 \mathrm{~mol} \%)$ are dissolved in acetonitrile and the solution is sparged for $10 \mathrm{~min} .0 .375 \mathrm{mmol}$ alkyne is added and the reaction irradiated with blue LED lamps $(427 \mathrm{~nm})$ for $16-20$ hours. ${ }^{\text {a }} 0.5 \mathrm{mmol}$ scale. 
to give rise to 2-azetine products. Specifically, converting 1-hexyne together with 2-isoxazoline 22 under otherwise identical reaction conditions afforded the desired 2-azetine product $\mathbf{5 1}$ in $34 \%$ yield (Table 3). Subsequent investigation of the scope of this transformation for aliphatic alkynes demonstrated tolerance of both internal $(\mathbf{5 2}, \mathbf{5 4})$ and terminal $(\mathbf{5 1}, \mathbf{5 3}, \mathbf{5 5}-\mathbf{5 9})$ alkynes in up to $28 \%$ and $58 \%$ yield respectively. Notably, larger alkynes bearing distal aryl substituents (44) were compatible with the optimal reaction conditions and resulted in the formation of the desired product in 55\% yield. Furthermore, alkynes with polar substituents including free alcohols resulted in the forming of the desired products $\mathbf{5 4 , 5 6}$, and $\mathbf{5 7}$ in up to $58 \%$ yield, which incorporate desirable handles for subsequent modifications. Additionally, isoxazolines bearing distinct substitution in the 5-position including a piperidine moiety, proved viable under the optimal conditions resulting in the desired product 58 in 55\% yield. Furthermore, a PMB ester group was similarly shown to be amenable to the optimal conditions, to provide $\mathbf{5 9}$ in $27 \%$ yield. Notably, successful formation of these 2 -azetine products relying on aliphatic alkynes also supports our hypothesis that 2-azetines represent viable intermediates in the reactions with aryl alkynes (Fig. 2).

We hypothesized that along with being valuable products, the 1-

Table 4. Functionalized Tetrahydrofurans via [2+2]-Cycloaddition of alkynes and 2-isoxazolines.

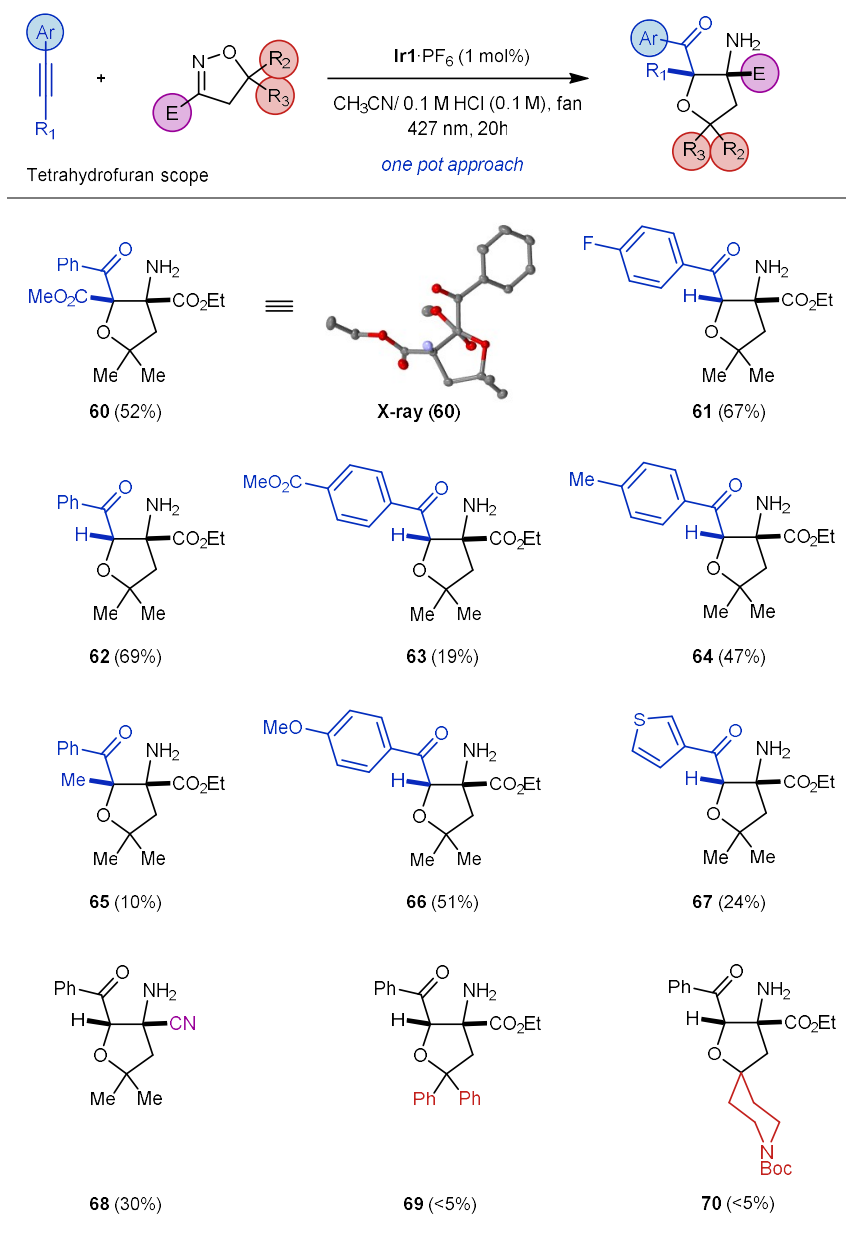

Conditions: $0.25 \mathrm{mmol}$ isoxazoline and $\mid \mathrm{r} 1 \cdot \mathrm{PF}_{6}(1 \mathrm{~mol} \%)$ are dissolved in $1: 1$ acetonitrile/ $0.1 \mathrm{M} \mathrm{HCl}(0.1 \mathrm{M})$ and the solution is sparged for $10 \mathrm{~min} .0 .375 \mathrm{mmol}$ alkyne is added and the reaction irradiated with blue LED lamps $(427 \mathrm{~nm})$ for $16-20$ hours. azetine products obtained could function as important buildingblocks for drug discovery. In subsequent investigations, we developed a one-pot method to access highly functionalized tetrahydrofuran products incorporating desirable amino-ester functionalities upon in-situ hydrolysis of initially formed intermediate 1azetines (Table 4). We anticipate that these products are desirable for pharmaceutical and drug discovery applications as amino esters and tetrahydrofurans both represent valuable synthetic scaffolds. 47,48a While numerous methods exist to access tetrahydrofurans ${ }^{47}$, the formation of densely substituted analogs is less established ${ }^{48}$ often resulting in either $1,4^{49}$ - or $1,2^{50}$-substitution patterns. In comparison, the method established herein relies on a single step, is diastereoselective and provides access to tetrahydrofuran products incorporating distinct 1,2,4-substitution. Initial investigation of the substrate scope revealed that terminal alkynes are well tolerated under the optimal reaction conditions relying on acetonitrile and aqueous $\mathrm{HCl}$. Specifically, alkynes bearing electron donating $(\mathbf{6 4 , 6 6 )}$ or electron withdrawing $(\mathbf{6 1 , 6 3})$ groups result in up to $51 \%$ or $67 \%$ yield, respectively. Para-fluoroaryl- substituted alkyne was an excellent substrate, forming $\mathbf{6 1}$ in $67 \%$. Interestingly, the tetrahydrofuran product (62) formed with phenylacetylene was the highest yielding product resulting in $69 \%$. Notably, the NMR yield obtained for the analogous 1 -azetine was $56 \%$, which suggests that the corresponding tetrahydrofuran product $\mathbf{6 2}$ is more stable than the analogous 1-azetine 29 (Table 1). Internal alkynes $(\mathbf{6 0 , 6 5})$ similarly proved compatible with the optimal reaction conditions, following the reactivity trend observed in the 1-azetine scope, resulting in up to $52 \%$ yield. Additionally, tetrahydrofurans 63 and 67 were synthesized in $19 \%$ and $24 \%$ yield respectively despite the fact that attempts to form the analogous 1-azetine resulted in exclusive decomposition. This is likely due to rapid conversion of the 1azetine product upon formation under the in-situ hydrolysis conditions. Although cyano- substituted isoxazoline substrates form the desired tetrahydrofuran $\mathbf{6 8}$ in $30 \%$ yield, the more sterically bulky isoxazolines bearing substituents in the 5-position fail to undergo the desired transformation $(\mathbf{6 9}, \mathbf{7 0})$, possibly due to decreased solubility in the aqueous reaction mixture.

Subsequent efforts centered on conducting mechanistic investigations to differentiate between a concerted or stepwise reaction pathway for the formation of 1-azetines from 2-azetine intermediates (Fig. 3). Initial control experiments demonstrated that both visible light and photocatalyst are essential for this reaction to proceed (see Supporting Information for details). Stern-Volmer quenching studies (Fig. 3a) demonstrated that while the 2-isoxazoline 22 quenched the catalyst as expected, diphenylacetylene (21) and phenylacetylene (28) exhibit quenching constants $\left(\mathrm{K}_{\mathrm{sv}}\right)$ comparable to that of 22. Cyclic voltammetry ruled out single electron transfer pathways as all the starting materials had redox potentials outside of the range of the photocatalyst used. Since quenching is indicative of interactions between the substrate and the catalyst excited state, this data suggests that both the isoxazoline $(\mathbf{2 2})$ and alkyne $(\mathbf{2 1}, \mathbf{2 8})$ reaction components could be sensitized to their triplet state by the photocatalyst, leading to triplet isoxazoline and triplet alkyne in the reaction mixture. As such, initiation of the [2+2] cycloaddition could be taking place from either the triplet state isoxazoline adding into a ground state alkyne, or a triplet state alkyne adding into the ground state isoxazoline.

To determine whether the 2-isoxazoline or the alkyne was initiating the cycloaddition reaction, a series of control experiments was carried out relying on diphenylacetylene $\mathbf{2 1}$, the strongest quencher of the photocatalyst identified in our Stern-Volmer studies. We hypothesized that if diphenylacetylene $\mathbf{2 1}$ was capable of initiating the 
Figure 3. Mechanistic Investigations Support a Stepwise Reaction Pathway for the Formation of 1-Azetines via Two Consecutive Electron Transfer Events.

A. 4-Memberec Nitrogen-Containing Heterocycles<smiles>CCOC(=O)C1=NOC(C)(C)C1</smiles>

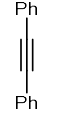

22

21

\begin{tabular}{|c|c|c|c|c|}
\hline $\mathrm{E}_{1 / 2}$ & $-2.01 \mathrm{~V}$ & $1.83 \mathrm{~V}$ & $2.06 \mathrm{~V}$ & \\
\hline $\mathrm{K}_{\mathrm{SV}}$ & $0.064 \mathrm{mM}^{--}$ & $0.4534 \mathrm{mM}^{-1}$ & $0.0459 \mathrm{mM}^{-1}$ & $0.006 \mathrm{mM}^{-1}$ \\
\hline
\end{tabular}

B. Oxime vs Alkyne Sensitization

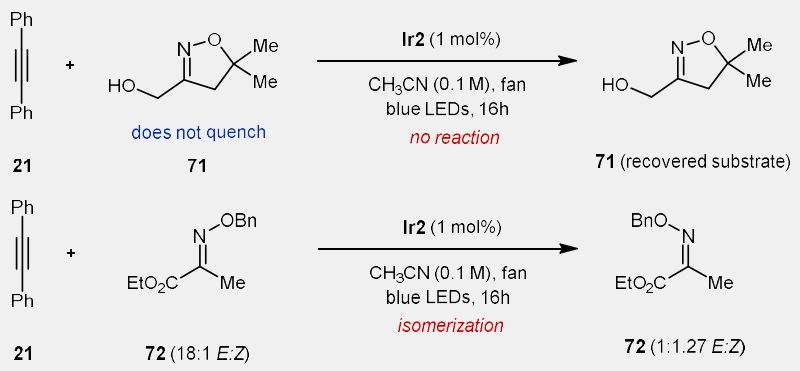

B. Mechanistic Support

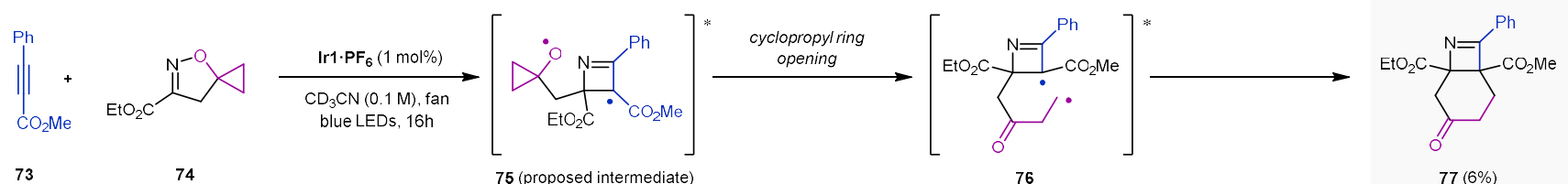

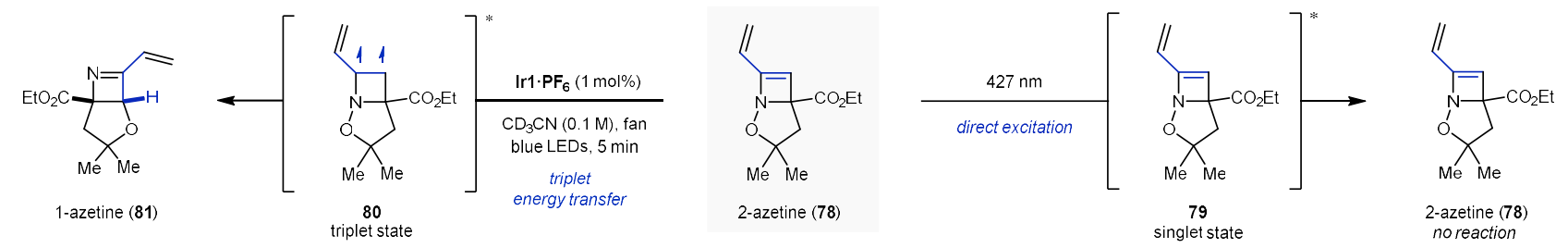

C. Current Mechanistic Hypothesis

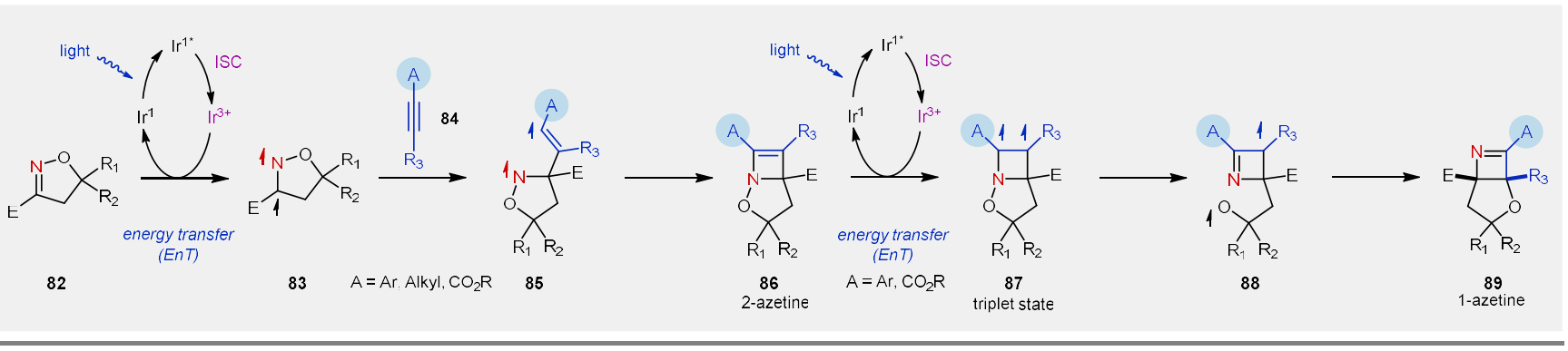

Conditions: For the conversion of 73 and $\mathbf{7 4}: 1$ equiv isoxazoline 74 was dissolved in $\mathrm{CD}_{3} \mathrm{CN}$ with 1.5 equiv 73 and 1 mol\% Ir1.PF in a screw top NMR tube. The mixture was sparged for 5 minutes with $\mathrm{N}_{2}$ and irradiated with blue LED lights for 16 hours. For the conversion of 78 with Ir1.PF 1 equiv 78 was dissolved in $\mathrm{CD}_{3} \mathrm{CN}_{\mathrm{N}}$ with 1 mol\% Ir1 $\cdot \mathrm{PF}_{6}$ in a screw top NMR tube. The mixture was sparged for 5 minutes with $\mathrm{N}_{2}$ and irradiated with blue LED lights for 5 minutes. For the conversion of 78 without catalyst under direct excitation: 1 equiv 78 was dissolved in $\mathrm{CD}_{3} \mathrm{CN}$ in a screw top NMR tube. The mixture was sparged for 5 minutes with $\mathrm{N}_{2}$ and irradiated with blue LED lights for 5 minutes.

[2+2] cycloaddition, we would see reactivity between $\mathbf{2 1}$ and oximes that cannot be sensitized by $\operatorname{Ir} 1 \cdot \mathrm{PF}_{6}$ and can therefore not initiate the $[2+2]$ cycloaddition themselves. To examine this we first utilized reduced 2-isoxazoline alcohol 71 which has previously been demonstrated as unreactive to triplet energy transfer. ${ }^{44}$ Notably, the reaction of 2-isoxazoline $\mathbf{7 1}$ with diphenylacetylene resulted in the exclusive recovery of 71, suggesting that diphenylacetylene is not initiating the [2+2]-cycloaddition. Similarly, reaction of diphenylacetylene 21 with acyclic oxime $\mathbf{7 2}$, which is known to undergo $E / Z$ isomerization following sensitization from the triplet state, precluding cycloaddition, failed to result in the formation of azetine products and resulted in the sole isolation of the isomerized substrate $\mathbf{7 2}$.

Next, mechanistic experiments were developed to gain additional insights into the conversion of 1 -azetines to 2 -azetine products (Fig.
3C). Specifically, we considered two possible mechanistic scenarios for this transformation; 1) a concerted 1,3-rearrangement from a singlet excited state accessible via direct excitation with $427 \mathrm{~nm}$ light; or 2) a stepwise triplet state rearrangement mediated by a second energy transfer step from the photocatalyst to the 2-azetine intermediate containing a styrene moiety (Figure 2). Based on the low triplet energy reported for styrenes of approximately $60 \mathrm{kcal} / \mathrm{mol}^{43}$ we hypothesized that a stepwise, triplet state mechanism could be operative. To probe for the viability of this hypothesis, we designed experiments capable of probing the presence of $O$-centered radicals formed upon $\mathrm{N}-\mathrm{O}$ cleavage in the intermediate 2-azetine. Particularly, we postulated that the reaction of 5-cyclopropyl isoxazoline $\mathbf{7 4}$ could result in the formation of ketone $\mathbf{7 7}$ upon cyclopropyl ring opening of intermediate $\mathbf{7 5}$ if the reaction were to proceed via $O$ centered radicals. Although the formation of ketone 77 was observed in only $6 \%$ yield, this result suggests that an $O$-centered radical can form upon $\mathrm{N}-\mathrm{O}$ bond cleavage. 
Subsequent efforts sought to distinguish between the possibility of direct excitation versus triplet energy transfer sensitization of the 2-azetine intermediate. Specifically, diene 78, accessed via mesylation and elimination of $\mathbf{5 7}$, was chosen as a viable probe as dienes have a triplet energy of $\sim 60 \mathrm{kcal} / \mathrm{mol},{ }^{43}$ enabling their excitation by the photocatalyst to access triplet state intermediate 80 (Fig. 3B). Indeed, conversion of diene $\mathbf{7 8}$ under otherwise optimal reaction conditions showed quantitative formation of 1-azetine $\mathbf{8 1}$ upon NMR-analysis. Notably, when conducting the reaction without Ir1 $\cdot \mathrm{PF}_{6}$ to probe the viability of direct excitation of $\mathbf{7 8}$ to singlet state 79 under the reaction conditions, no conversion was observed. Together, these experiments are consistent with a stepwise triplet energy transfer driven mechanism for these conditions, rather than a singlet state mechanism driven by direct excitation. ${ }^{51}$

On the basis of these studies, we propose the following mechanism (Fig 3C). Upon sensitization of the 2-isoxazoline $\mathbf{8 2}$ by triplet energy transfer from the triplet state iridium photocatalyst, biradical $\mathbf{8 3}$ is formed, which subsequently adds into the alkyne 84. Notably, the generation of this more stable biradical $\mathbf{8 5}$ determines the regioselectivity observed. 85 subsequently undergoes intersystem crossing to the singlet state, from where radical recombination results in the 2-azetine intermediate (86). Notably, for 2-azetines formed from aliphatic alkynes, the 2-azetine product is unable to undergo further energy transfer from the photocatalyst, and thus represents the final product. In comparison, 2-azetines formed from activated alkynes undergo a second sensitization from the triplet iridium catalyst to generate a triplet biradical 87. This triggers cleavage of the $\mathrm{N}-\mathrm{O}$ bond to result in $\mathbf{8 8}$ incorporating an imine and an $O$-centered radical, which undergoes ensuing intersystem crossing back to the singlet state, followed by radical recombination to result in the formation of 1-azetine $\mathbf{8 9}$.

We describe the development of a visible light-mediated, divergent approach to 1- and 2-azetine products relying on activated or aliphatic alkynes, respectively. Mechanistic studies are consistent with a rearrangement of activated 2-azetine intermediates induced upon triplet energy transfer. We anticipate this method will provide a valuable addition to the current repertoire for medicinal chemists to obtain previously inaccessible, highly functionalized azetines, allowing for the exploration of these unique and interesting scaffolds in current drug design and development. Notably, this new approach is advantageous compared to previously established methods for 1- and 2-azetine syntheses, which often require complex reagents and/or harsh conditions.

\section{ASSOCIATED CONTENT}

Supporting Information. The Supporting Information is available free of charge on the ACS Publications website and includes experimental procedures, characterization $\left({ }^{1} \mathrm{H}-\mathrm{NMR},{ }^{13} \mathrm{C}-\mathrm{NMR}\right.$, IR, and MS data), additional optimization and control experiments (pdf format).

\section{AUTHOR INFORMATION}

\section{Corresponding Author}

* Email: corinnas@umich.edu.

\section{Author Contributions}

The manuscript was written through contributions of all authors. All authors have given approval to the final version of the manuscript.
Notes

The authors declare no competing financial interests.

\section{ACKNOWLEDGMENT}

We thank the Alfred P. Sloan Foundation, the David and Lucile Packard Foundation the Camille and Henry Dreyfus Foundation, and NIH (R01-GM141340) for funding. E.R.W. thanks the National Science Foundation for a predoctoral fellowship. We thank Prof. C. R. J. Stephenson for helpful discussions regarding the mechanistic investigations.

\section{REFERENCES}

(1) a) Scannell, J. W.; Blanckley, A.; Boldon, H.; Warrington, B. Dianosing the Decline in Pharmaceutical R\&D Efficiency. Nat. Rev. Drug Discov. 2012, 11 (3), 191-200. https://doi.org/10.1038/nrd3681; b) Shih, H. P.; Zhang, X.; Aronov, A. Drug discovery effectiveness from the standpoint of therapeutic mechanisms and indications. Nat Rev Drug Discov. 2018, 17, 19-33. https://doi.org/10.1038/nrd.2017.194

(2) Wild, H.; Heimbach, D.; Huwe, C. Editorial: The Importance of Chemistry for the Future of the Pharma Industry. Angew. Chem. Int. Ed. 2011, $50 \quad$ (33), 7452-7453. https://doi.org/10.1002/anie.201103888.

(3) Goldberg, F. W.; Kettle, J. G.; Kogej, T.; Perry, M. W. D.; Tomkinson, N. P. Designing Novel Building Blocks Is an Overlooked Strategy to Improve Compound Quality. Drug Discov. Today 2015, 20 (1), 11-17. https://doi.org/10.1016/j.drudis.2014.09.023.

(4) Marson, C. M. New and Unusual Scaffolds in Medicinal Chemistry. Chem. Soc. Rev. 2011, 40 (11), 5514-5533. https://doi.org/10.1039/C1CS15119C.

(5) Sun, H.; Tawa, G.; Wallqvist, A. Classification of Scaffold-Hopping Approaches. Drug Discov. Today 2012, 17 (7), 310-324. https://doi.org/10.1016/j.drudis.2011.10.024.

(6) Böhm, H.-J.; Flohr, A.; Stahl, M. Scaffold Hopping. Drug Discov. Today Technol. 2004, 1 (3), 217-224. https://doi.org/10.1016/j.ddtec.2004.10.009.

(7) Bauer, M. R.; Di Fruscia, P.; Lucas, S. C. C.; Michaelides, I. N.; Nelson, J. E.; Storer, R. I.; Whitehurst, B. C. Put a Ring on It: Application of Small Aliphatic Rings in Medicinal Chemistry. RSC Med. Chem. 2021, 12 (4), 448-471. https://doi.org/10.1039/D0MD00370K.

(8) Brown, A.; Brown, T. B.; Calabrese, A.; Ellis, D.; Puhalo, N.; Ralph, M.; Watson, L. Triazole Oxytocin Antagonists: Identification of an Aryloxyazetidine Replacement for a Biaryl Substituent. Bioorg. Med. Chem. Lett. 2010, 20 (2), 516-520. https://doi.org/10.1016/j.bmcl.2009.11.097.

(9) Fish, P. V.; Brown, A. D.; Evrard, E.; Roberts, L. R. 7-Sulfonamido3-Benzazepines as Potent and Selective 5-HT2C Receptor Agonists: Hit-to-Lead Optimization. Bioorg. Med. Chem. Lett. 2009, 19 (7), 1871-1875. https://doi.org/10.1016/j.bmcl.2009.02.071.

(10) Lowe, J. T.; Lee, M. D.; Akella, L. B.; Davoine, E.; Donckele, E. J.; Durak, L.; Duvall, J. R.; Gerard, B.; Holson, E. B.; Joliton, A.; Kesavan, S.; Lemercier, B. C.; Liu, H.; Marié, J.-C.; Mulrooney, C. A.; Muncipinto, G.; Welzel-O’Shea, M.; Panko, L. M.; Rowley, A.; Suh, B.-C.; Thomas, M.; Wagner, F. F.; Wei, J.; Foley, M. A.; Marcaurelle, L. A. Synthesis and Profiling of a Diverse Collection of Azetidine-Based Scaffolds for the Development of CNS-Focused Lead-like Libraries. J. Org. Chem. 2012, 77 (17), 7187-7211. https://doi.org/10.1021/jo300974j.

(11) Maetani, M.; Zoller, J.; Melillo, B.; Verho, O.; Kato, N.; Pu, J.; Comer, E.; Schreiber, S. L. Synthesis of a Bicyclic Azetidine with In Vivo Antimalarial Activity Enabled by Stereospecific, Directed C(Sp3)-H Arylation. J. Am. Chem. Soc. 2017, 139 (32), 11300 11306. https://doi.org/10.1021/jacs.7b06994. 
(12) St. Jean, D. J.; Fotsch, C. Mitigating Heterocycle Metabolism in Drug Discovery. J. Med. Chem. 2012, 55 (13), 6002-6020. https://doi.org/10.1021/jm300343m.

(13) Lovering, F.; Bikker, J.; Humblet, C. Escape from Flatland: Increasing Saturation as an Approach to Improving Clinical Success. J. Med. Chem. 2009, 52 (21), 6752-6756. https://doi.org/10.1021/jm901241e.

(14) Lovering, F. Escape from Flatland 2: Complexity and Promiscuity. MedChem Comm 2013, 4 (3), 515-519. https://doi.org/10.1039/C2MD20347B.

(15) Glas, A. F.; Kaya, E.; Schneider, S.; Heil, K.; Fazio, D.; Maul, M. J.; Carell, T. DNA (6-4) Photolyases Reduce Dewar Isomers for Isomerization into (6-4) Lesions. J. Am. Chem. Soc. 2010, 132 (10), 3254-3255. https://doi.org/10.1021/ja910917f.

(16) Haiser, K.; Fingerhut, B. P.; Heil, K.; Glas, A.; Herzog, T. T.; Pilles, B. M.; Schreier, W. J.; Zinth, W.; de Vivie-Riedle, R.; Carell, T. Mechanism of UV-Induced Formation of Dewar Lesions in DNA. Angew. Chem. Int. Ed. 2012, 51 (2), 408-411. https://doi.org/10.1002/anie.201106231.

(17) Douki, T.; Rebelo-Moreira, S.; Hamon, N.; Bayle, P.-A. DNA Photochemistry: Geometrically Unconstrained Pyrimidine (6-4) Pyrimidone Photoproducts Do Photoisomerize. Org. Lett. 2015, 17 (2), 246-249. https://doi.org/10.1021/ol5033267.

(18) Smetanin, I. A.; Novikov, M. S.; Agafonova, A. V.; Rostovskii, N. V.; Khlebnikov, A. F.; Kudryavtsev, I. V.; Terpilowski, M. A.; Serebriakova, M. K.; Trulioff, A. S.; Goncharov, N. V. A Novel Strategy for the Synthesis of Thermally Stable and Apoptosis-Inducing 2,3-Dihydroazetes. Org. Biomol. Chem. 2016, 14 (19), 4479-4487. https://doi.org/10.1039/C6OB00588H.

(19) Drug-like Properties: Concepts, Structure Design and Methods | ScienceDirect https://www.sciencedirect.com/book/9780123695208/drug-like-properties-conceptsstructure-design-and-methods (accessed 2021 -06 -08).

(20) Baumann, A. N.; Eisold, M.; Music, A.; Haas, G.; Kiw, Y. M.; Didier, D. Methods for the Synthesis of Substituted Azetines. Org. Lett. 2017, 19 (20), 5681-5684. https://doi.org/10.1021/acs.orglett. $7 \mathrm{~b} 02847$.

(21) Guillemin, J. C.; Denis, J. M.; Lablache-Combier, A. 1-Azetine: Thermal Ring Opening to 2-Azabutadiene. J. Am. Chem. Soc. 1981, 103 (2), 468-469. https://doi.org/10.1021/ja00392a041.

(22) Bock, H.; Dammel, R. Gasphasen-Reaktionen, 611) Cycloalkanimine 2H-Azirin, 1-Azetin, 1-Pyrrolin, 1-Piperidein und 3,4,5,6Tetrahydro-2H-azepin: Darstellung und Photoelektronen-Spektren2,3). Chem. Ber. 1987, 120 (12), 1971-1985. https://doi.org/10.1002/cber.19871201209.

(23) Hassner, A.; Levy, A. B. Stereochemistry. LXIII. Pyrolysis of Cyclopropyl Azides. Route to 1-Azetines. J. Am. Chem. Soc. 1971, 93 (8), 2051-2053. https://doi.org/10.1021/ja00737a037.

(24) Hassner, A.; Currie, J. O.; Steinfeld, A. S.; Atkinson, R. F. Chemistry of Small Rings. 20. Reactions of Azirines. Carbene and Carbenoid Reactions. J. Am. Chem. Soc. 1973, 95 (9), 2982-2987. https://doi.org/10.1021/ja00790a041.

(25) Harnisch, J.; Szeimies, G. Darstellung Und Thermisches Verhalten von Azidocyclopropanen. Chem. Ber. 1979, 112 (12), 3914-3933. https://doi.org/10.1002/cber.19791121216.

(26) a) Smetanin, I.A.; Novikov, M.S.; Rostovskii, N.V.; Khlebnikov, A.F.; Starova, G.L.; Yufit, D.S. 4-Halo-2-azabuta-1,3-dienes as intermediates in the rhodium carbenoid-initiated transformation of 2 halo- $2 \mathrm{H}$-azirines into 2,3-dihydroazetes and 2,5-dihydrooxazoles. Tetrahedron 2015, 71, 4616-4628. https://doi.org/10.1016/j.tet.2015.05.022; b) Novikov, M.S.; Khlebnikov, A.F.; Rostovskii, N.V.; Tcyrulnikov, S.; Suhanova, A.A.; Zavyalov, K.V.; Yufit, D.S. Pseudopericyclic 1,5- versus Pericyclic 1,4- and 1,6-Electrocyclization in Electron-Poor 4-Aryl- 2-azabuta-1,3-dienes: Indole Synthesis from $2 \mathrm{H}$-Azirines and $\mathrm{Di}$ azo Compounds. J. Org. Chem. 2015, 80, 18-29. https://doi.org/10.1021/jo501051n.

(27) Jung, M. E.; Choi, Y. M. New Synthesis of 2-Azetines and 1Azabutadienes and the Use of the Latter in Diels-Alder Reactions: Total Synthesis of (.+-.)-.Delta.-Coniceine. J. Org. Chem. 1991, 56 (24), 6729-6730. https://doi.org/10.1021/jo00024a001.

(28) Marchand, A. P.; Rajagopal, D.; Bott, S. G.; Archibald, T. G. Reactions of 1-Ethyl-3-Azabicyclo[1.1.0]Butane with Electrophiles. A Facile Entry into New, N-Substituted 3-Ethylideneazetidines and 2-Azetines. J. Org. Chem. 1994, 59 (7), 1608-1612. https://doi.org/10.1021/j000086a008.

(29) Dejaegher, Y.; Mangelinckx, S.; De Kimpe, N. Rearrangement of 2-Aryl-3,3-Dichloroazetidines: Intermediacy of 2-Azetines. $J$. Org. Chem. 2002, $67 \quad$ (7), 2075-2081. https://doi.org/10.1021/jo010914j.

(30) Mangelinckx, S.; Speybroeck, V. V.; Vansteenkiste, P.; Waroquier, M.; Kimpe, N. D. Experimental and Computational Study of the Conrotatory Ring Opening of Various 3-Chloro-2-Azetines. $J$. Org. Chem. 2008, 73 (14), 5481-5488. https://doi.org/10.1021/jo800522b.

(31) Yavari, I.; Nematpour, M. Copper-Catalyzed One-Pot Synthesis of Functionalized 1,4-Dihydroazete Derivatives from Sulfonyl Azides, Terminal Alkynes, and Tetramethylguanidine. Synlett 2012, 23 (15), 2215-2218. https://doi.org/10.1055/s-0032-1317075.

(32) Schiele, C.; Kalinowski, H. O. Synthesis of 1'-Methylspiro [3HNaphtho[2,1-b]-Pyran-3,2'(1,2-Dihydroquinoline)]. Angew. Chem. Int. Ed. Engl. 1966, 5 (4), 416-416. https://doi.org/10.1002/anie.196604161.

(33) Reiners, F.; Joseph, E.; Niß1, B.; Didier, D. Stereoselective Access to Azetidine-Based $\alpha$-Amino Acids and Applications to Small Peptide Synthesis. Org. Lett. 2020, 22 (21), 8533-8537. https://doi.org/10.1021/acs.orglett.0c03131.

(34) Cantrell, T. S. Photochemical Cycloadditions of Benzonitrile to Alkenes. Factors Controlling the Site of Addition. J. Org. Chem. 1977, 42 (26), 4238-4245. https://doi.org/10.1021/jo00862a014.

(35) Yang, N.-C. C.; Kim, B.; Chiang, W.; Hamada, T. Photochemical Synthesis of 1-Azetines. J. Chem. Soc. Chem. Commun. 1976, No. 18, 729-730. https://doi.org/10.1039/C39760000729.

(36) Barluenga, J.; Gómez, A.; Santamaría, J.; Tomás, M. Sequential Five-Component Construction of the Cyclopenta[e][1,3]Oxazine Skeleton Using Stable 2-Azetine Derivatives. Angew. Chem. Int. Ed. 2010, $49 \quad$ (7), 1306-1308. https://doi.org/10.1002/anie.200906357.

(37) Hara, S.; Ito, S. TiCl4-Mediated [2+2] Cycloaddition for Synthesis of Isolable CF3-Substituted 2-Azetines. Asian J. Org. Chem. 2021. https://doi.org/10.1002/ajoc.202100082.

(38) Funes-Ardoiz, I.; González, J.; Santamaría, J.; Sampedro, D. Understanding the Mechanism of the Divergent Reactivity of NonHeteroatom-Stabilized Chromium Carbene Complexes with Furfural Imines: Formation of Benzofurans and Azetines. J. Org. Chem. 2016, 81 (4), 1565-1570. https://doi.org/10.1021/acs.joc.5b02729.

(39) Lopez, S. A.; Houk, K. N. Substituent Effects on Rates and Torquoselectivities of Electrocyclic Ring-Openings of N-Substituted 2-Azetines. J. Org. Chem. 2014, 79 (13), 6189-6195. https://doi.org/10.1021/j0500919s.

(40) Didier, D.; Baumann, A. N.; Eisold, M. Unsaturated Four-Membered N-Heterocycles: From Synthesis to Applications. Tetrahedron Lett. 2018, $59 \quad$ (45), 3975-3987. https://doi.org/10.1016/j.tetlet.2018.09.055.

(41) Guillemin, J.-C.; Denis, J.-M.; Lasne, M.-C.; Ripoll, J.-L. Synthese d'imines cycliques non-stabilisees par reactions gaz-solide sous vide et thermolyse-eclair $(1,2)$. Tetrahedron 1988, 44 (14), 4447-4455. https://doi.org/10.1016/S0040-4020(01)86146-9. 
(42) Khlebnikov, A. F.; Novikov, M. S. Ring Expansions of Azirines and Azetines. In Topics in Heterocylic Chemistry; Springer International, 2015; Vol. 41, pp 143-232.

(43) Ni, T.; Caldwell, R. A.; Melton, L. A. The Relaxed and Spectroscopic Energies of Olefin Triplets. J. Am. Chem. Soc. 1989, 111 (2), 457-464. https://doi.org/10.1021/ja00184a008.

(44) Becker, M. R.; Wearing, E. R.; Schindler, C. S. Synthesis of Azetidines via Visible-Light-Mediated Intermolecular [2+2] Photocycloadditions. Nat. Chem. 2020, 12 (10), 898-905. https://doi.org/10.1038/s41557-020-0541-1.

(45) Richardson, A. D.; Becker, M. R.; Schindler, C. S. Synthesis of Azetidines by Aza Paternò-Büchi Reactions. Chem. Sci. 2020, 11 (29), 7553-7561. https://doi.org/10.1039/D0SC01017K.

(46) Becker, M. R.; Richardson, A. D.; Schindler, C. S. Functionalized Azetidines via Visible Light-Enabled Aza Paternò-Büchi Reactions. Nat. Commun. 2019, $10 \quad$ (1), 5095. https://doi.org/10.1038/s41467-019-13072-x.

(47) Aurélien de la Torre, Claire Cuyamendous, Valérie Bultel-Poncé, Thierry Durand, Jean-Marie Galano, et al.. Recent advances in the synthesis of tetrahydrofurans and applications in total synthesis. Tetrahedron 2016, $72 \quad$ (33), 5003-5025. https://doi.org/10.1016/j.tet.2016.06.076

(48) a) Wales, S. M.; Merison, E. G.; Adcock, H. V.; Pearce, C. A.; Strutt, I. R.; Lewis, W.; Hamza, D.; Moody, C. J. Diastereoselective Synthesis of Highly Substituted, Amino- and Pyrrolidino-Tetrahydrofurans as Lead-Like Molecular Scaffolds. Chem. Eur. J. 2018, 24, 8233-8239. https://doi.org/10.1002/chem.201801046; b) Verdugo, F.; da Concepción, E. Rodiño, R.; Calvelo, M.; Mascareñas, J. L.; López, F. Pd-Catalyzed (3+2) Heterocycloadditions between Alkylidenecyclopropanes and Carbonyls: Straightforward Assembly of Highly Substituted Tetrahydrofurans. ACS Catal. 2020, $10 \quad$ (14), 7710-7718 https://doi.org/10.1021/acscatal.0c01827; c) Brooks, J. L.; Xu, L.;
Wiest, O.; Tan. D. S. Diastereoselective Synthesis of Highly Substituted Tetrahydrofurans by Pd-Catalyzed Tandem Oxidative Cyclization-Redox Relay Reactions Controlled by Intramolecular Hydrogen Bonding. J. Org. Chem. 2017, 82 (1), 57-75. https://doi.org/10.1021/acs.joc.6b02053

(49) a) Lee, S.; Bae, H. Y.; List, B. Can a Ketone Be More Reactive than an Aldehyde? Catalytic Asymmetric Synthesis of Substituted Tetrahydrofurans. Angew. Chem. Int. Ed. 2018, 57, 12162-12166. https://doi.org/10.1002/anie.201806312; b) Brooks, J. L.; Xu, L.; Wiest, O.; Tan. D. S. Diastereoselective Synthesis of Highly Substituted Tetrahydrofurans by Pd-Catalyzed Tandem Oxidative Cyclization-Redox Relay Reactions Controlled by Intramolecular Hydrogen Bonding. J. Org. Chem. 2017, 82 (1), 57-75. https://doi.org/10.1021/acs.joc.6b02053.

(50) Xie, Y.; Cheng, G. J.; Lee, S.; Kaib, P. S. J.; Thiel, W.; List, B. Catalytic Asymmetric Vinylogous Prins Cyclization: A Highly Diastereo- and Enantioselective Entry to Tetrahydrofurans. J. Am Chem. Soc. 2016, 138 (44), 14538-14541. https://doi.org/10.1021/jacs.6b09129.

(51) A [2+2]-cycloaddition between alkynes and alkenes leading to cyclobutanes was recently reported, which was suggested to rely on the excitation and rearrangement of intermediate styrenes: Ha, S.; Lee, Y.; Kwak, Y.; Mishra, A.; Yu, E.; Ryou, B.; Park, C.-M. Alkyne-Alkene [2 + 2] Cycloaddition Based on Visible Light Photocatalysis. Nat. Commun. 2020, $11 \quad$ (1), 2509. https://doi.org/10.1038/s41467-020-16283-9. 